\title{
IMPLANTAÇÃO DO PROGRAMA 5S EM UMA ESCOLA MUNICIPAL
}

\author{
Elaine Patussi da Silva ${ }^{1}$ \\ Katarinny Pinto Sena Deles ${ }^{1}$ \\ Vérica Marconi Freitas de Paula ${ }^{2}$
}

\begin{abstract}
RESUMO: O Programa 5S pretende que as pessoas consigam tornar o seu ambiente mais harmonioso e agradável, por meio da implantação de algumas práticas, contribuindo para o melhor desenvolvimento de suas atividades. Este texto analisa a implantação do Programa 5S em uma escola da rede municipal de ensino de uma cidade do Triângulo Mineiro, realizada por meio de um projeto de extensão proposto por membros da Universidade Federal de Uberlândia(UFU). O projeto foi conduzido por uma equipe de facilitadores que auxiliou na constituição e orientou a Equipe de Qualidade da escola, constituída por professores e funcionários, para a implantação dos três primeiros Sensos. O projeto apresentou um resultado satisfatório quanto ao melhor aproveitamento dos espaços e dos recursos disponibilizados, assim como em relação à participação das pessoas. $\mathrm{O}$ grande desafio da comunidade escolar é manter os resultados alcançados e promover novos avanços.
\end{abstract}

PALAVRAS-CHAVE: Programa 5S. Gestão da qualidade. Educação.

The implementation of the $5 S$ program in a public school

\begin{abstract}
The 5S Program intends to help people so they can make their environment more pleasant and harmonious, through the implementation of some practices that would contribute to a better development of their activities. This paper analysis the implementation of the program in a Brazilian public school in a city of the Triângulo Mineiro region, in the state of Minas Gerais, Brazil. The project was carried out through an extension project proposed by members of the Federal University of Uberlandia (UFU). It was conducted by a facilitating team that helped in its production and guided the Quality Team of the school, which consisted of teachers and other employees, in the implementation of the first three surveys. The 5S Program reached satisfactory outcomes, as better use of resources and people participation. The school community's big deal is to keep the results and to go forward.
\end{abstract}

KEYWORDS: 5S Program. Quality management. Education.

\section{INTRODUÇÃO}

A escola exerce grande influência na formação de cidadãos, e o desenvolvimento da sociedade depende muito da qualidade dos serviços prestados nos ambientes educacionais. Para Schmidt e colaboradores (2000), a escola cumpre função fundamental de auxiliar no desenvolvimento

\footnotetext{
${ }^{1}$ Graduandas em Engenharia de Produção pela Universidade Federal de Uberlândia (elainepatussi6@gmail.com; katarinnysena@hotmail.com).

2 Doutora em Engenharia de Produção pela Universidade de São Paulo, professora na Faculdade de Gestão e Negócios da Universidade Federal de Uberlândia (verica@terra.com.br). 
das pessoas, contribuindo para a formação de cidadãos que saibam o seu papel na sociedade e sejam atuantes na contribuição para melhorar a comunidade em que estão inseridos.

Dessa forma, a escola assume um importante papel, além da sua função primária de propiciar oportunidades e condições de aprendizado aos alunos, qual seja: a de formadora de pessoas como agentes atuantes na sua família, na sua comunidade e no seu país.

O Censo da Educação no Brasil, de 2010, aponta que, dos alunos matriculados na educação básica, mais de $85 \%$ estão na escola pública, o que denota sua importância e influência na formação inicial dos brasileiros (BRASIL, 2012; RODRIGUES, 2010). Nesse contexto, a escola pública pode ser vista como uma propulsora na inserção e na formação de novas ideias e conceitos, viabilizando a implantação de mudanças de aspectos sociais e culturais em médio e longo prazo. Por outro lado, é importante considerar o paradoxo restrição orçamentária versus demanda de alunos versus necessidade de oferecer a formação mais adequada aos estudantes. Todos os recursos alocados às escolas devem ser muito bem utilizados, viabilizando os investimentos em novas tecnologias e melhoria das condições de trabalho e aprendizagem.

Considerando isso, ferramentas de Gestão da Qualidade surgem como uma opção para auxiliar a escola pública no cumprimento de seu papel de fomentador de instrução e conhecimentos técnicos e de formador dos cidadãos do amanhã. Práticas simples, usualmente empregadas por organizações privadas, ainda carecem de maior utilização na área pública. Para Torquato Jr. e Araújo (2008), apesar de algumas particularidades, como o atendimento igualitário a todos e a descontinuidade dos gestores, os Programas de Qualidade podem ser mais amplamente utilizados, especialmente na esfera pública.

Uma das bases da Gestão da Qualidade é o Programa 5S, cujo objetivo principal é promover a mudança comportamental das pessoas, proporcionando total reorganização do ambiente por meio da eliminação de materiais inúteis, identificação destes materiais, execução constante de limpeza no local de trabalho e construção de um ambiente que proporcione saúde física e mental (REBELLO, 2005).

Algumas experiências pontuais têm evidenciado o Programa 5S como uma ferramenta útil para auxiliar a construção de hábitos mais saudáveis nas escolas, englobando várias pessoas, como os profissionais, os alunos e a própria comunidade na qual a escola está inserida (COSTA; PENO; BOSCHI, 1996). Para Schmidt e colaboradores (2008), a implantação das práticas propostas pelo Programa 5S em escolas - que vão desde a organização de ambientes até o desenvolvimento da autodisciplina - podem contribuir para a formação do cidadão, já que reforça preceitos éticos.

Este texto analisa a implantação do Programa 5S em uma escola da rede pública municipal de ensino no Triângulo Mineiro por meio de um projeto de extensão proposto por membros da Universidade Federal de Uberlândia. O projeto de extensão realizado objetivou apresentar os principais conceitos do Programa 5S à comunidade escolar, bem como auxiliar a sua efetiva implantação na escola estudada.

Além desta seção, que apresenta a contextualização do estudo realizado, o texto está dividido em cinco seções: "O Programa 5S", que destaca os princípios teóricos do 5S; na sequência, é apresentada a "Caracterização da escola"; a terceira seção trata da descrição do procedimento para implantação do programa na escola - "Implantação do Programa 5S"; a quarta seção, 
denominada "Resultados e Discussão", mostra os principais resultados do projeto; e, finalmente, a seção "Considerações Finais" discute os aspectos mais marcantes da implantação do Programa.

\section{O Programa 5S}

Originário do Japão pós-guerra, o Programa 5S é formado por cinco palavras japonesas iniciadas pela letra S (Seiri, Seiton, Seiso, Seiketsu e Shitsuke) e tem por objetivo promover melhorias nas instituições e no relacionamento entre as pessoas, além de propiciar mudança de hábitos e atitudes. No Brasil, o Programa é conhecido com acréscimo da palavra "Senso" antes de cada expressão, que tenta representar o conteúdo daquele termo específico: Senso de Utilização; Senso de Organização; Senso de Limpeza; Senso de Saúde e Higiene; Senso de Autodisciplina.

Como o objetivo deste artigo é descrever a implantação dos primeiros três Sensos do Programa 5S em uma escola pública municipal, somente os três primeiros serão, aqui, brevemente detalhados.

a. Seiri (Senso de Utilização): é o primeiro Senso a ser implantado e seu conceito serve para verificar quais objetos são úteis em determinado local, sendo que as partes inúteis devem ser descartadas, podendo ter utilidade para outros fins (FIGUEIRA et al. 2004). De acordo com Ribeiro (1999), esse Senso significa saber utilizar sem desperdiçar. Trata-se de uma atividade bem simples: analisar e separar os objetos (como equipamentos, documentos e outros materiais de consumo) necessários dos desnecessários e dar um destino adequado aos que não são mais utilizados. A palavra "utilização" resume o primeiro Senso, pois caracteriza sua prática, ou seja, manter somente os itens que tem utilidade em um local. Além disso, é necessário combater o hábito de guardar os objetos desnecessários. É preciso identificar o porquê do excesso de materiais, adotando medidas preventivas para evitar o acúmulo de itens que não têm proveito naquele local.

b. Seiton (Senso de Organização): é o segundo Senso a ser implantado. Seu conceito é especificar um local para cada objeto (que tenha sido considerado como útil ou necessário no primeiro Senso), alocando-o e mantendo-o em seu devido lugar após a utilização. Dessa forma, a localização dos itens e a sua consequente utilização por todas as pessoas é facilitada. De acordo com Rebello (2005, p. 170), esse Senso "refere-se à disposição sistemática dos objetos com excelente comunicação visual, utilização de etiquetas para identificação [...] a fim de que se possam manter as coisas do jeito que devem ser". Organizar significa colocar as coisas nos lugares corretos ou distribuídos de determinada maneira, para que possam ser utilizadas prontamente (OSADA, 2010). É uma das formas mais simples para se evitar o desperdício de tempo e o esforço com a localização dos objetos.

c. Seiso (Senso de Limpeza): manter o ambiente limpo é o significado desse Senso. Para colocá-lo em prática, as pessoas passam a ser responsáveis pela limpeza e conservação de seus ambientes, examinando possíveis fontes da sujeira e as eliminando para que esse ambiente possa estar sempre limpo e agradável a seus usuários (RIBEIRO, 1999). 
Para Oliani, Silva e Sacomano (2006), esse Senso significa acabar com a sujeira e retirar objetos estranhos, a fim de manter limpo o local de trabalho, sendo que o descarte do lixo, de sujidades e de outros materiais sem aproveitamento deve ser feito com menor intervenção possível ao meio ambiente.

Em linhas gerais, O Programa 5S propõe basicamente a determinação de organizar e limpar determinado ambiente, mantendo as condições requeridas à execução das atividades e a disciplina necessária para se ter um ambiente mais adequado (REBELLO, 2005).

\section{Caracterização da escola}

A escola em que o projeto de extensão foi implantado funciona nos períodos matutino e vespertino, tendo 232 alunos matriculados no período matutino e 256 no vespertino, totalizado 488 estudantes. A escola atende, principalmente, à população urbana, representando $92 \%$ do total de alunos.

O turno matutino é composto por 12 turmas (duas salas de $4^{\circ}$ ano, $5^{\circ}$ ano, $6^{\circ}$ ano, $7^{\circ}$ ano e $9^{\circ}$ ano; uma sala do $8^{\circ}$ ano; e uma sala de reforço). Já o período vespertino é formado por 13 turmas (três salas de $3^{\circ}$ ano e $5^{\circ}$ ano; duas salas de $2^{\circ}$ ano e $3^{\circ}$ ano; e uma sala de reforço).

A escola possui 67 funcionários, sendo: 49 professores, 12 funcionários (envolvidos em atividades como limpeza, refeitório, biblioteca e secretaria), três supervisores, um diretor e dois vice-diretores.

No último resultado do Índice de Desenvolvimento da Educação Básica (Ideb/2011), objetivando avaliar a qualidade da educação básica a partir da progressão ao longo dos anos e da aprendizagem, a escola obteve nota de 5.4. O valor é considerado positivo, estando $23 \%$ acima da meta da escola prevista para o ano. Apesar de o resultado ser superior à média brasileira, é inferior à média do município em que a escola está situada (BRASIL, 2011).

\section{Implantação do Programa 5S}

A equipe de facilitadores da implantação do Programa 5S na escola foi composta por três pessoas, que exerceram diferentes papéis durante a execução do projeto, sendo um coordenador e dois agentes.

Após a definição e a formalização da escola participante, foi realizada uma visita para apresentação da equipe de facilitadores à direção e discussão detalhada sobre as etapas de implantação do projeto.

Na sequência, foi agendada uma reunião com todos os professores, ainda visando apresentar a equipe de facilitadores e o projeto para a comunidade escolar. Essa reunião inicial teve também o objetivo de despertar o interesse das pessoas em participar da Equipe de Qualidade da escola. A proposição inicial previa que a Equipe de Qualidade da escola deveria ser composta por representantes de 
todos os envolvidos na comunidade escolar, ou seja, professores, alunos, pais e funcionários.

A definição da Equipe da Qualidade visou envolver pessoas da escola, a fim de que a implantação do Programa fosse realizada conforme as características da escola, para a multiplicação dos preceitos do Programa 5S, e, principalmente, para garantir a continuidade da prática do $5 \mathrm{~S}$ de forma independente da presença da equipe de facilitadores na escola. Considerando esses objetivos, os membros da Equipe da Qualidade participaram de um treinamento específico para conhecer a origem, os objetivos e as etapas de implantação do 5S na escola.

Para motivar e estimular o envolvimento de toda a comunidade escolar, os princípios do Programa 5S foram apresentados a toda a comunidade escolar (alunos, professores, funcionários administrativos e direção), ressaltando os possíveis benefícios para a escola, para a sociedade e para cada pessoa, conforme será descrito na sequência.

Antes da apresentação do Programa aos alunos, foram elaborados e dispostos por toda a escola cartazes tratando de temas relacionados aos aspectos contemplados pelo $5 \mathrm{~S}$, visando despertar o interesse e a curiosidade dos alunos sobre o que seria realizado na escola (Figura 1).

Figura 1 - Exemplo de cartazes utilizados para divulgação do Programa 5S.
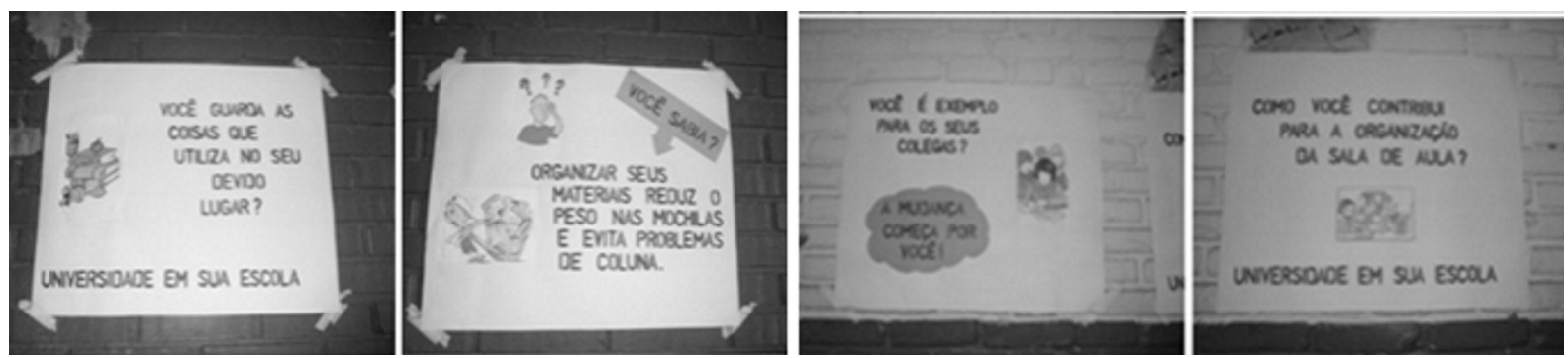

Fonte: Material do projeto (2012).

A partir de então, os Sensos foram implantados de maneira consecutiva em cada setor, respeitando as necessidades individuais e o período indicado pela Equipe da Qualidade para a adaptação e o entendimento de cada conceito apresentado.

\section{Implantação do Senso de Utilização}

A implantação do Senso de Utilização foi realizada em três etapas: Divulgação, Vistoria e Ação, abaixo descritas. 


\section{$1^{a}$ Etapa do Senso de Utilização: Divulgação}

O Programa foi apresentado para os alunos e professores em cada sala de aula, o que possibilitou realizar uma apresentação de acordo com cada faixa etária, utilizando recursos visuais e exemplos. Além disso, foi elaborado um material informativo contendo dicas para aplicação do primeiro Senso no seu ambiente e mostrada a importância de reforçar, no dia-a-dia, os principais conceitos desse Senso para os alunos, estimulando-os na prática de novos hábitos. Cartazes explicando e incentivando a prática do Primeiro Senso foram colocados na escola para lembrar as pessoas sobre o que precisaria ser feito e como poderia ser feito (Figura 2).

Figura 2 - Exemplo de cartazes utilizados para divulgação do Senso de Utilização.
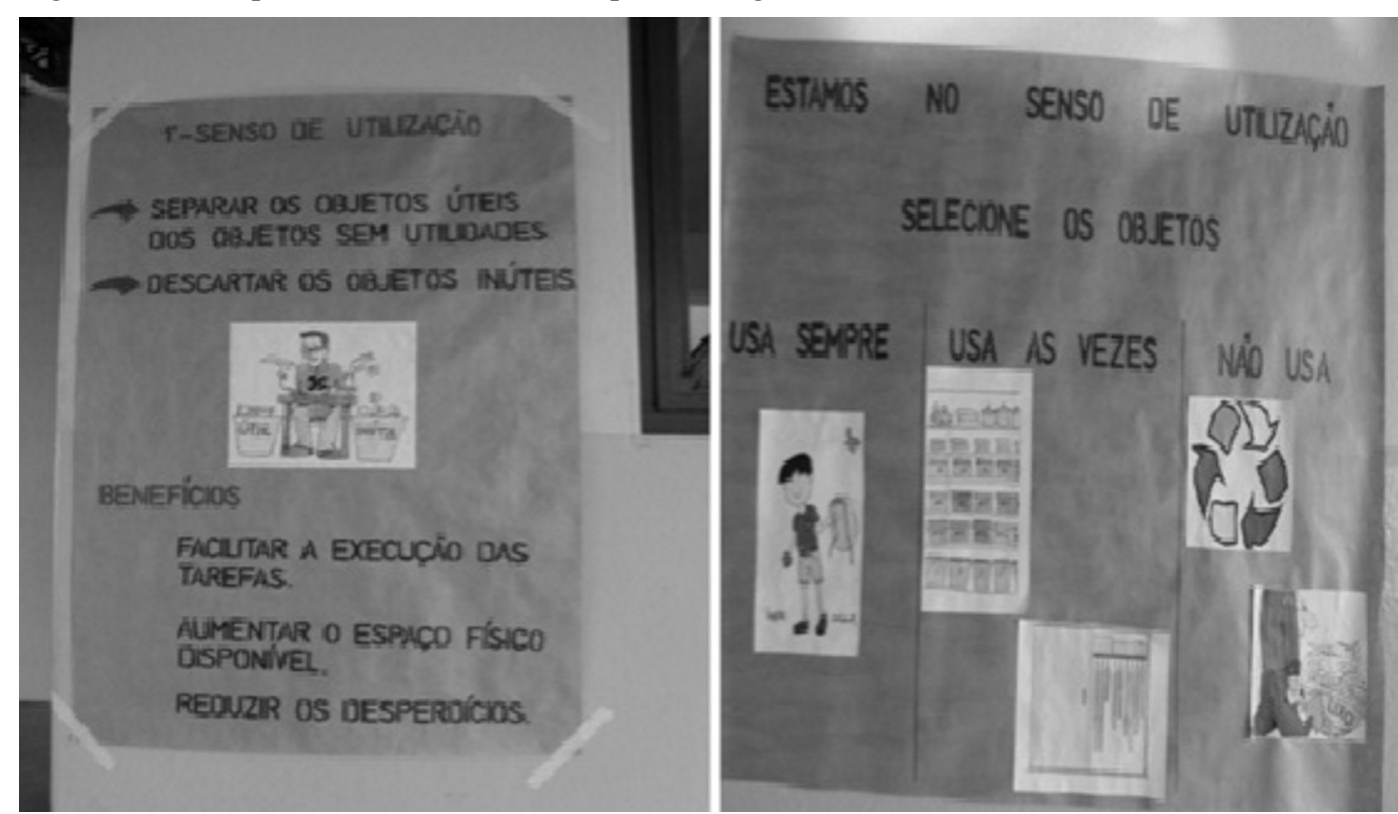

Fonte: Material do Projeto (2012).

\section{$2^{\text {a }}$ Etapa do Senso de utilização: Vistoria}

Nessa etapa, foi realizado um diagnóstico em todas as áreas e espaços da escola com auxílio de um dos membros da Equipe da Qualidade, visando identificar os objetos que não tinham mais utilidade na instituição, sendo que cada um desses objetos foi classificado segundo seu provável destino: doação, conserto, reciclagem ou descarte. O Quadro 1 demonstra parte da lista com alguns materiais e a definição de sua destinação. 
Quadro 1 - Exemplo de classificação dos objetos no Senso de Utilização.

\begin{tabular}{|c|c|}
\hline Recursos inúteis & Destino \\
\hline Rede rasgada & Descartar \\
\hline Televisões antigas & Doar \\
\hline Bebedouro & Consertar \\
\hline Capela & Reciclar \\
\hline
\end{tabular}

Fonte: Elaborado pelos autores.

\section{$3^{\text {a }}$ Etapa do Senso de Utilização: Ação}

Nessa fase, foi apresentada a lista materiais e equipamentos não utilizados à direção da escola, que disponibilizou uma sala para alocação dos itens (Sala de Descarte). Os alunos participaram dessa etapa, auxiliando no transporte dos objetos sem utilidade que estavam em um depósito, dispondo-os de forma organizada naquela sala.

Alguns recursos novos (nunca utilizados, por não ter sido realizada a sua instalação) a serem utilizados pela escola, como televisões e ar condicionados, foram identificados com uma placa "Separados pelo Senso de Utilização" e armazenados em outro local com acesso restrito. Apesar de já solicitado pela escola, o profissional responsável pela instalação ainda não fora designado pela Prefeitura. Nesse momento, todos os funcionários foram também estimulados a selecionar material e/ou equipamento que não utilizavam em seu espaço de trabalho e a levá-los para sala de descarte.

É importante ressaltar que a maioria dos materiais classificados como sem utilidade compunha o patrimônio da escola, estando registrado e inventariado dessa maneira. Assim, qualquer destinação a ser dada a esse material (como remoção, descarte, doação ou venda) requereria informação ao setor responsável na Prefeitura Municipal, sendo necessária a sua anuência. Dessa forma, a eliminação do material sem utilidade na escola requereu a realização de um procedimento administrativo, conforme determinado em lei, por se tratar de uma instituição pública.

\section{Implantação do Senso de Organização}

Aimplantaçãodo SensodeOrganizaçãofoi dividida em duas etapas: DivulgaçãoeAção, abaixodescritas. 


\section{$1^{\text {a }}$ Etapa do Senso de Organização: Divulgação}

Os conceitos do Senso de Organização foram apresentados para alunos, professores e demais funcionários por meio de cartazes e material informativo (Figura 3). Foi realizada, também, uma apresentação em sala, em que foram ressaltadas as mudanças ocorridas na escola até então e a importância da atuação de todos para que as salas fossem mantidas organizadas.

Figura 3- Exemplo de cartazes utilizados para divulgação do Senso de Organização.

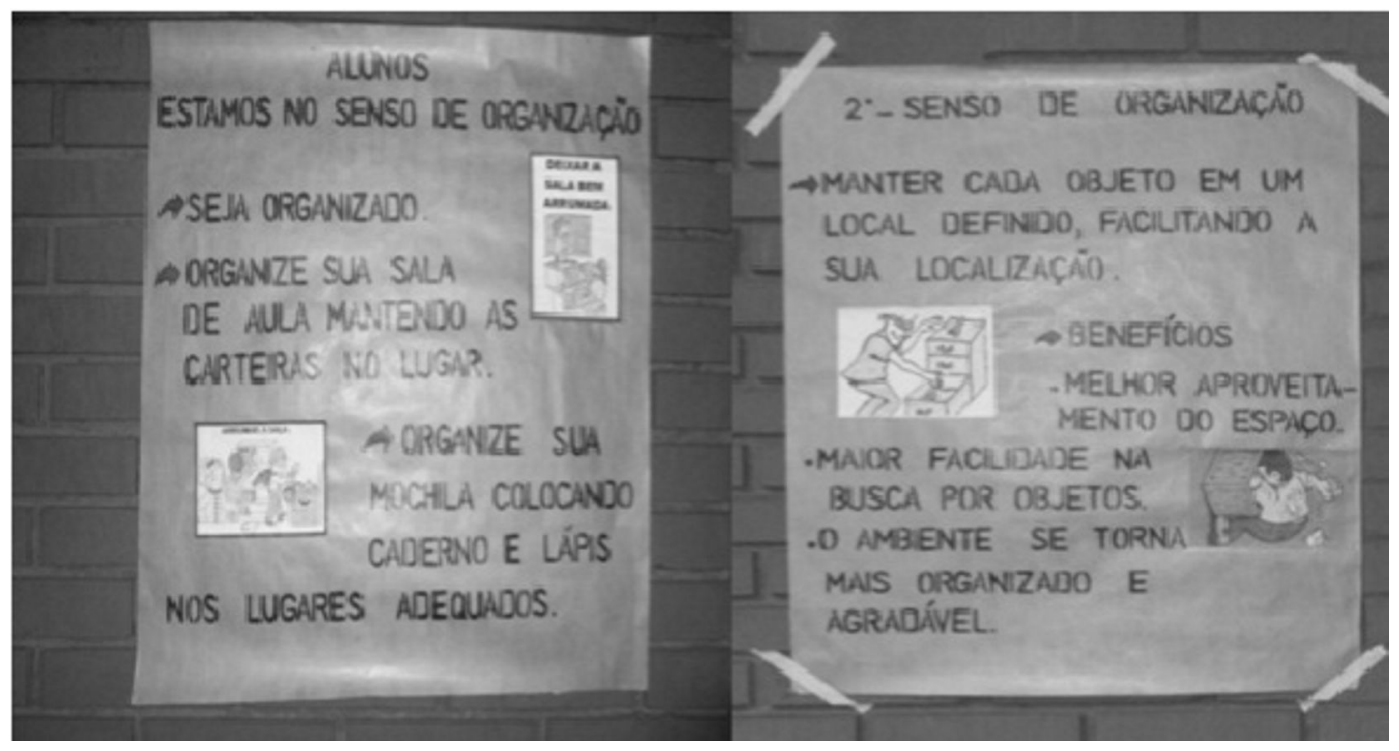

Fonte: Material do Projeto (2012).

Os cartazes evidenciaram os benefícios dos Sensos e as atitudes necessárias para padronizar a organização do espaço escolar. O material informativo ressaltou a importância de os professores darem o exemplo, mantendo a organização dos armários presentes em cada sala.

\section{$2^{a}$ Etapa do Senso de Organização: Ação}

Nessa etapa, cada setor foi organizado a partir da delimitação de um espaço específico para cada objeto, identificado por etiquetas. Essa padronização foi realizada em todos os locais da escola: depósitos, biblioteca, refeitório, salas de aula, armários dos professores, salas da direção e secretaria. 


\section{Implantação do Senso de Limpeza}

Aimplantação do Senso de Limpeza foi realizada por meio da apresentação dos seus princípios para os alunos, visando estimular sua autocrítica em relação aos hábitos de escrever nas carteiras e paredes e de jogar lixo no chão. Cartazes foram utilizados nos pátios da escola, informando os princípios do Senso de Limpeza e seus benefícios, assim como o papel de todos para a consecução dos objetivos (Figura 4).

Figura 4 - Exemplo de cartazes utilizados para divulgação do Senso de Limpeza.
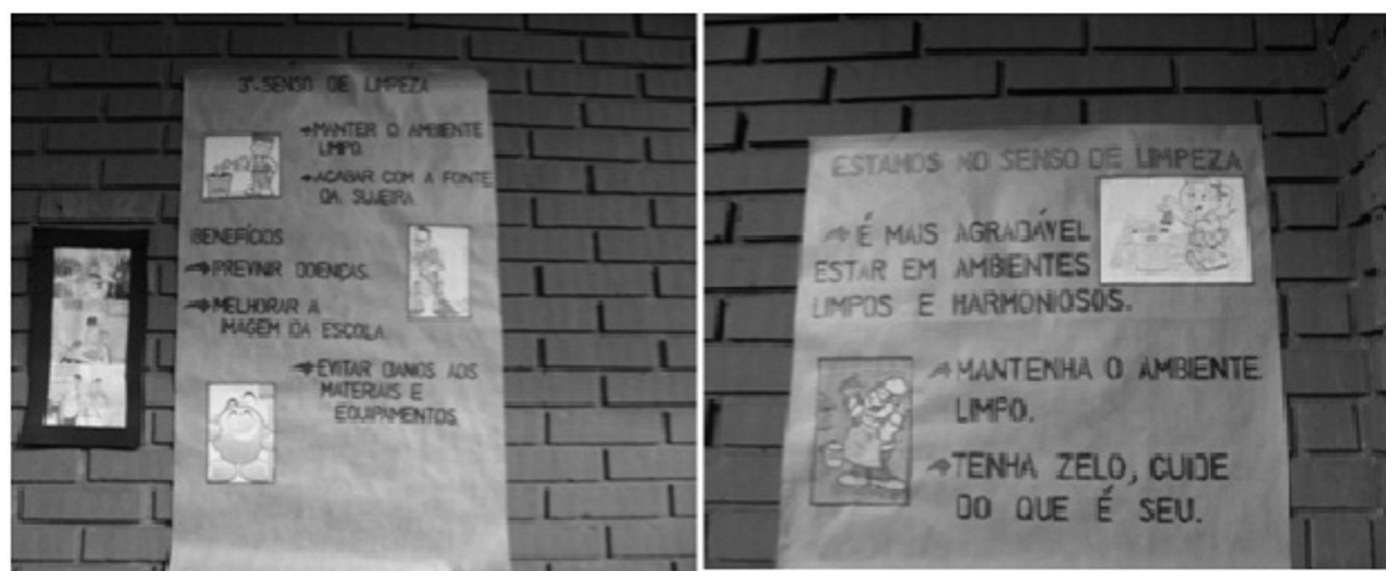

Fonte: Material do Projeto (2012).

Assim como nos dois primeiros Sensos, foi entregue um informativo aos professores e funcionários, ressaltando a necessidade de eles estimularem e relembrarem a seus alunos a relevância de preservar os recursos da escola e a importância de se ter um ambiente sempre limpo e bem conservado.

\section{RESULTADOS E DISCUSSÃO}

Após a implantação dos três Sensos, foi possível observar, na escola, alguns dos resultados e benefícios esperados com a implantação do Programa 5S. Alguns funcionários listaram aspectos como: melhoria da arrumação e organização; liberação de espaço físico; maior acessibilidade aos recursos; ambiente de trabalho limpo após as atividades.

Imagens de alguns espaços da escola, antes da implantação e após a implantação dos três Sensos do Programa 5S, discutidos anteriormente, demonstram os efeitos e os benefícios do trabalho realizado pela comunidade da escola (Figura 5). 
Figura 5 - Imagens do antes e depois da implantação dos três sensos na escola.
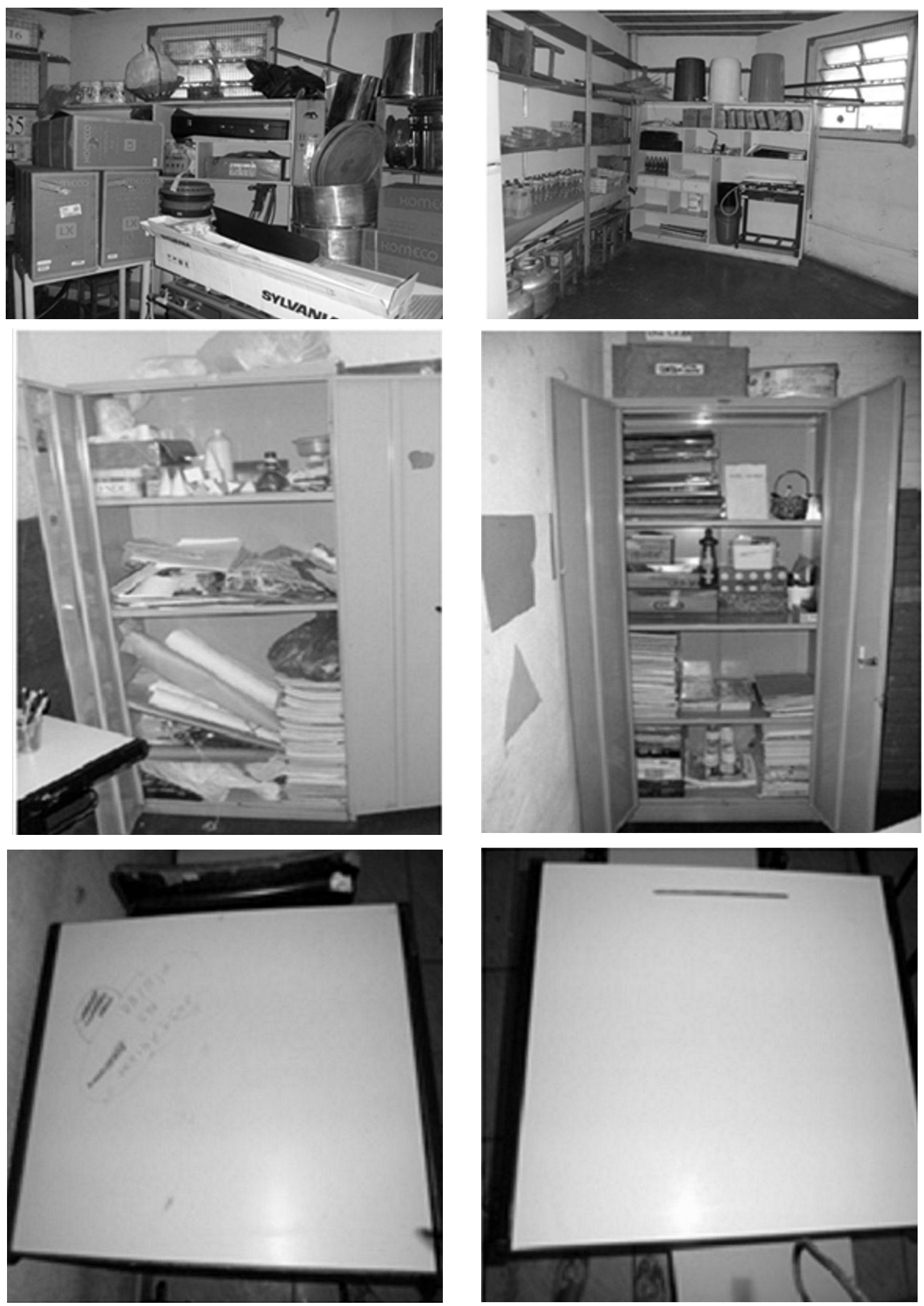

Fonte: Material do Projeto (2012). 


\section{CONSIDERAÇÕES FINAIS}

Foi possível observar, na escola, alguns dos resultados decorrente do trabalho em conjunto da Equipe da Qualidade com outros participantes da comunidade escolar. As atividades realizadas, relacionadas aos três primeiros Sensos do Programa 5S, objetivaram, entre outros aspectos: melhorar a utilização dos recursos no ambiente escolar, por meio do descarte ou doação dos objetos sem utilidade; organizar as diferentes áreas da escola, estabelecendo a disposição dos objetos e facilitando o acesso aos recursos necessários; criar condições de manter a limpeza, especialmente nos espaços comuns e nas salas de aula; e divulgar práticas de colaboração para a manutenção dos ambientes limpos e organizados.

Os resultados centrais obtidos com a implantação dos três primeiros Sensos foram: maior satisfação dos funcionários com seu ambiente de trabalho; melhor organização dos recursos; redução do desperdício de materiais; ambiente escolar mais limpo.

É importante comentar que a implantação dos três primeiros Sensos estendeu-se mais do que o previsto, uma vez que foi necessário programar um tempo maior para a realização de cada uma das etapas, o que não prejudicou o resultado da implantação dos Sensos, apenas retardou a obtenção dos resultados.

A principal dificuldade encontrada foi o envolvimento efetivo de toda escola. Apesar de diversas tentativas, por diversos caminhos diferentes, não foi possível motivar toda a comunidade escolar a conhecer e a utilizar os princípios do Programa. Esse fato pode comprometer a permanência dos novos hábitos, já que algumas pessoas não os assimilaram e, possivelmente, manterão seus antigos hábitos.

Durante as apresentações dos Sensos, embora receptivos aos novos conceitos, houve, por parte do alunado, frequentes dúvidas sobre qual seria o retorno direto da participação deles no programa. Nesta direção, foi possível desenvolver ideias dos benefícios para o ambiente escolar e para a vida pessoal e profissional de cada um deles, demonstrando que bons hábitos melhorariam sua qualidade de vida e que pessoas mais organizadas e autoconfiantes tendem a criar melhores oportunidades para o desenvolvimento pessoal e coletivo.

Outra grande dificuldade encontrada foi lidar com os trâmites da administração pública. A própria questão do descarte de materiais sem utilidade requer um processo administrativo, levando algum tempo e exigindo a realização de atividades adicionais pela área administrativa da escola. Além disso, algumas ações a serem realizadas na escola (como instalação de equipamentos eletrônicos, montagem de prateleiras, reforma de carteiras e cadeiras, pintura da escola) dependiam da liberação de profissional da Prefeitura Municipal ou mesmo de liberação para a sua realização, o que ainda ficou pendente.

Por outro lado, é importante comentar que a direção da escola demonstrou comprometimento com as atividades do projeto, o que garantiu os bons resultados, pois a liderança incentivava e apoiava a realização das atividades necessárias. Alinhado a isso, a Equipe da Qualidade formada na escola agiu prontamente, realizando seu trabalho com afinco e dedicação.

É perceptível que a implantação do Programa 5S contribuiu para que a escola melhorasse sua 
organização interna, ampliasse o espaço físico disponível e facilitasse o acesso aos recursos, melhorando seu aproveitamento e conservação. O Programa demonstrou ser uma ferramenta simples e de baixo custo, com potencial de auxiliar os ambientes educacionais no alcance de alguns dos seus desafios.

A mudança de hábitos propostas pelo Programa requer, porém, dedicação e esforço pessoal de cada envolvido, sendo um nível de dedicação difícil de ser obtido, a menos que haja persistência de algumas pessoas na condução e no reforço dos princípios. Dessa forma, a escola já atingiu grandes resultados, sendo um desafio mantê-los ao longo do tempo, e um desafio, ainda maior, avançar no patamar das melhorias alcançadas.

\section{AGRADECIMENTOS}

Agradecemos à Pró-reitoria de Extensão, Cultura e Assuntos Estudantis da Universidade Federal de Uberlândia pelo apoio concedido por meio do Edital PEIC/UFU/PROEX/029/2011.

\section{REFERÊNCIAS}

BRASIL. O Brasil em números. 2012. Disponível em: < http://www.brasil.gov.br/sobre/obrasil/o-brasil-em-numeros-1/educacao>. Acesso em: 13 dez. 2012.

BRASIL. Ministério da Educação. Índice de Desenvolvimento da Educação Básica (Ideb). Prova Brasil. 2011. Disponível em <http://www.portalideb.com.br>. Acesso em: 21 nov. 2012.

COSTA, R. M. C.; PENO, S. do N.; BOSCHI, C. M. Como praticar o $5 S$ na escola. Belo Horizonte: Editora QFCO, 1996.

FIGUEIRA, C. S. et. al. Programa 5S: um caso de insucesso. In: CONGRESSO VIRTUAL BRASILEIRO DE ADMINISTRAÇÃO (CONVIBRA), 4., 2004, São Paulo. Anais... Disponível em: <http://www.convibra.com.br/2004/pdf/85.pdf>. Acesso em: 14 dez. 2012.

OLIANI, L. H.; SILVA, E. C. C.; SACOMANO, J. B. Qualidade e meio ambiente: proposta para implantação do Programa 5S + A. ENCONTRO NACIONAL DE ENGENHARIA DE PRODUÇÃO (ENEGEP), 26., 2006, Fortaleza. Anais... Disponível em: < http://www.abepro. org.br/biblioteca/ENEGEP2006_TR520347_8680.pdf>. Acesso em: 21 nov. 2012.

OSADA, T. Housekeeping 5 "S": seiri, seiton, seiso, seiketsu, shitsuke. São Paulo: Instituto IMAM, 2010.

REBELLO, M. A. de F. R. Implantação do Programa 5S para a conquista de um ambiente de qualidade na Biblioteca do Hospital Universitário da Universidade de São Paulo. Revista Digital de Biblioteconomia e Ciência da Informação, Campinas, v. 3, n. 1, p. 165-182, jul./dez. 2005.

RIBEIRO, H. 5S administrativo. São Paulo: PDCA Editora, 1999. 
RODRIGUES, C. Total de alunos cai na rede pública e cresce na particular. Disponível em: $<$ http://ultimosegundo.ig.com.br/educacao/total + de + alunos + cai + na + rede + publica + e + cresce $+n$ a+particular/n1237901720181.html>. Acesso em: 13 dez. 2012.

SCHMIDT, A. S. et. al. A implantação do Programa 5S na Escola Padre Nóbrega. ENCONTRO NACIONAL DE ENGENHARIA DE PRODUÇÃO (ENEGEP), 20., 2000, São Paulo. Anais... Disponível em: < http://www.abepro.org.br/biblioteca/ENEGEP2000_E0216.PDF>. Acesso em: 21 nov. 2012.

TORQUATO JR., S.; ARAÚJO, M. A. D. Avaliação do Programa 5 "S” em uma instituição de ensino. Revista de Gestão, São Paulo, v. 15, n. 2, p. 79-97, abr.jun. 2008.

Submetido em 6 de janeiro de 2013.

Aprovado em 22 de julho de 2013. 